\title{
An update of patterns of care and outcomes for men diagnosed with prostate cancer in Victoria
}

Running head: Patterns of care for men with prostate cancer

Luke L. Wang ${ }^{1} M B B S, B M e d S c i$, Kirobel Begashaw ${ }^{1} M P H, B B i o m e d S c i$, Melanie Evans $^{2} B S c, M P H$, Arul Earnest ${ }^{2} P h D, M S c$, Sue M Evans ${ }^{2}$ Master Clin Epi, PhD, Jeremy L. Millar ${ }^{3,4} M B C h B, F R A N Z C R$, Declan G Murphy5,6 MBBCH, FRACS, Daniel Moon $^{1,4,5}$ MBBS(Hon), FRACS(Urology)

Institutional affiliations:

1 Australian Urology Associates, Malvern, Victoria, Australia

2 School of Public Health and Preventive Medicine, Monash University, Victoria, Australia

3 Radiation Oncology, Alfred Health, Victoria, Australia

4 Department of Surgery, Central Clinical School, Monash University, Victoria, Australia

5 Division of Cancer Surgery, Peter MacCallum Cancer Centre, Melbourne, Victoria, Australia

6 Sir Peter MacCallum Department of Oncology, Univeristy of Melbourne, Parkville, Victoria, Australia.

This is the author manuscript accepted for publication and has undergone full peer review but has not been through the copyediting, typesetting, pagination and proofreading process, which may lead to differences between this version and the Version of Record. Please cite this article as doi: $10.1111 /$ ans.14722

This article is protected by copyright. All rights reserved. 
Address for correspondence:

Dr Luke Wang

Australian Urology Associates,

Malvern,

Victoria, Australia

Tel: 0385063600

Fax: 0385063699

Email: drlukewang@gmail.com

Corresponding author is not a recipient of a research scholarship.

Disclosure of sources of financial support: none.

Potential conflict of interest: none.

Tables: 2

Supplement information:

- Tables: 4

- Figure: 1

Word count:

This article is protected by copyright. All rights reserved. 
- Abstract: 242

- Text: 2522

\begin{abstract}
:
Backgrounds:

To update patterns of care for men diagnosed with prostate cancer in Victoria, Australia, between 2008 and 2015.
\end{abstract}

\title{
Materials and methods:
}

From August 2008 to December 2015, 14,025 men diagnosed with prostate cancer were included. These data were obtained from the Prostate Cancer Outcome Registry - Victoria (PCOR-Vic). Frequencies were used to describe hospital and patient characteristics and treatment types. Comparisons were made between previous period of analysis (2008-2011) to the most recent period (2011-2015). Survival analysis using a stepwise Cox proportional hazards regression model was performed.

This article is protected by copyright. All rights reserved. 


\section{Results:}

Mean age of diagnosis was 66.5 years and $44 \%$ of patients were diagnosed with Gleason 7 prostate cancer. Majority of notifications (63.6\%) were received from a private institution and $70.2 \%$ of patients were diagnosed at a metropolitan institution. Most patients (95.3\%) were diagnosed with clinically localised disease. Within 12 months of diagnosis, 55.9\% of patients with low risk disease received no active treatment. Radical prostatectomy (RP) was the most common primary treatment with curative intent (47\%). When comparing of patterns of care between 2008-2011 and 2011-2015, the proportion of patients diagnosed with Gleason 9-10 disease increased, as has the proportion of patients diagnosed with metastatic disease.

\section{Conclusion:}

With the PCOR-Vic, we were able to identify that increasing number of patients were diagnosed with high-risk and metastatic disease. There has been an overall decrease in radical treatment rates, likely due to active surveillance playing a significant role especially in patients with low risk prostate cancer.

This article is protected by copyright. All rights reserved. 
Keywords: prostate cancer, patterns of care, registry, health services research

\section{Introduction}

Australia has one of the highest incidences of prostate cancer in the world ${ }^{1}$, representing a major public health issue and placing a significant burden on health resources. Between 2008 and 2012, the Australian Institute of Health and Welfare ${ }^{2}$ estimated that there were over 94,000 men living with prostate cancer.

In 1993, the epidemiology and management of prostate cancer in Victoria were first reported through a large population-based survey ${ }^{3}$. To more comprehensively and prospectively monitor treatment and outcomes for men 
following a prostate cancer diagnosis, the Prostate Cancer Outcome RegistryVictoria (PCOR-Vic, formally known as the Victorian Prostate Cancer Registry (Vic-PCR)) was established in 2009. Evans et $\mathrm{al}^{4}$ first reported the patterns of care for men with prostate cancer from this population-based registry. Further analysis of PCOR-Vic has described the use of active surveillance for localised prostate cancer ${ }^{5}$, positive surgical margins in men undergoing radical prostatectomy ${ }^{6}$, and quality improvements seen in both of these areas over the duration of PCOR-Vic .

Of note, since the inception of PCOR-Vic, there have been significant developments in prostate cancer diagnosis and management in relation to PSA screening 8,9 , randomised trials comparing prostatectomy to observation ${ }^{10,11,12}$, or comparing radical prostatectomy to radiation or active monitoring ${ }^{13}$. Finally, we have also seen an increase in the utilisation of active surveillance as a management strategy for low risk disease ${ }^{7,14,15}$. The grade D recommendation of the United States Preventive Services Taskforce (USPSTF) against PSA testing in 2012 resonated very strongly, and despite efforts to mitigate the negative messaging regarding early detection of prostate cancer ${ }^{16}$, there has been a significant reduction in PSA testing, prostate biopsies, and diagnoses of prostate cancer, not just in the USA ${ }^{17}$, but also in Canada ${ }^{18}$ and Australia ${ }^{19}$. 
In this rapidly shifting landscape of prostate cancer management, we aim to update the patterns of care and outcomes in Victorian men with prostate cancer. By comparing patterns of care in 2008-2011 to 2011-2015, shifting trends influenced by new guidelines and evidence may be identified.

\section{Methods}

The purpose of the PCOR-Vic is to monitor patterns of care and outcomes of men diagnosed with prostate cancer in Victorian hospitals. Details of PCOR-Vic and methods of data collection have been previously described ${ }^{20}$. We analysed data in PCOR-Vic to determine patterns of care of men diagnosed with prostate cancer between 2008 and 2015, and to identify temporal changes during this period.

\section{Inclusion and exclusion criteria}

Patients were included in this study if they had a statutorily-required notification to the Victorian Cancer Registry of a histological diagnosis of prostate cancer between $1^{\text {st }}$ August 2008 and 31 ${ }^{\text {st }}$ December 2015, and had also attended at a participating hospital with both ethical approval from the recruiting hospital's human research ethics committee and consent from clinicians to include all their patients in the registry. 
Recruitment and data collection

Notifications from 33 public and six private institutions were progressively added to PCOR-Vic. Following notification of prostate cancer diagnosis, an explanatory statement was sent to the patient approximately 10 months after diagnosis explaining that their information would be included in the registry unless they chose to opt off.

Clinical details and histopathological data were collected from medical records, or extracted from hospital information systems and pathology reports prior to the 12-month telephone follow-up. The phone call was used to administer a quality of life tool and confirm PSA levels and treatment details. Treatments provided within 12 months of diagnosis were included in the analysis.

Statistical Analysis

Frequencies were used to describe hospital and patient characteristics. Proportions were also used to describe treatment types according to National Comprehensive Cancer Network (NCCN) risk of disease progression categories. The very low risk NCCN category was not used because PCOR-Vic does not collect PSA density, necessary for this assignment. If a patient had a Gleason score $\leq 6$ and a PSA level $<10 \mathrm{ng} / \mathrm{ml}$ at diagnosis but there was no clinical T stage 
recorded, they were classified as having low risk disease. For treatment analysis, patients who were recorded as 'active surveillance' or 'watchful waiting', and patients who had no documentation of treatment, were recorded as having no active treatment within 12 months of their diagnosis.

A multivariate logistic regression analysis was also undertaken using these categorical predictor variables to assess the odds of not receiving treatment. Furthermore, for the descriptive characteristics, treatment frequencies, analysis compared the previous period of analysis (2008-2011) to the most recent period (2011-2015).

Survival analysis using a stepwise Cox proportional hazards regression model (probability of inclusion $=0.05$ ) was undertaken to assess characteristics associated with mortality. All statistical analyses were performed using STATA/IC version 14.2 (StataCorp, College Station, TX), and a two-sided P value $<0.05$ was considered statistically significant.

\section{Ethics Approval}

Institutional review board approval for this project was obtained from Monash University's Human Research Ethics Committee (Review reference 2016-09991070).

This article is protected by copyright. All rights reserved. 


\section{Results}

Recruitment

The recruitment of patients into PCOR-Vic are summarised in FigureS1. A total of 19,319 prostate cancer notifications were assessed for eligibility by PCOR-Vic. In total, 2,975 men (15.4\%) were ineligible. Of the 16,344 who were eligible, 426 patients did not provide consent for participation and 185 consents were pending. Of the 15,733 men who did not opt out of the registry, treatment details were collected on 14,025 (89\%) men.

\section{Hospital and patient characteristics}

Hospital and patient characteristics are summarised in Table 1 . The majority of patients were diagnosed at metropolitan hospitals (70.2\%) and there were more than twice the number of notifications from the private sector $(63.6 \%)$ compared to that of the public (31\%). Years with the highest number of notifications of diagnosis were in 2011 and 2012, accounting for 17.3 and $17.7 \%$ respectively. Mean age at diagnosis was 66.5 years (SD=8.99). Median PSA level was 6.8 (interquartile range $=4.8-11 \mathrm{ng} / \mathrm{mL}$ ). The majority of the patients 
$(13,366,95.3 \%)$ were classified as having clinically localised disease, and $43.3 \%$ (6070) of the patients were classified as being at intermediate risk of disease progression.

\section{Management details}

Management types and their breakdown according to risk of disease in the initial 12 months following diagnosis are summarised in Table 2. A total of 3349 (23.9\%) patients received no active treatment. Of the 3466 patients with low risk disease, 1937 (55.9\%) received no active treatment. Comparing public and private sectors, $25.4 \%$ and $24.1 \%$ of patients received no active treatment, respectively; $24.5 \%$ of patients from metropolitan and $24.6 \%$ of regional patients received no active treatment. Radical prostatectomy (RP) was the most common primary treatment with curative intent (47\%). Of the patients who underwent RP, 2.3\% did not have an approach recorded. Of those that did, 55.7\% of the cases were robotic-assisted RP, 38.2\% had open RP and 6.1\% had laparoscopic approach. Comparing public and private, $28.7 \%$ and $50.2 \%$ of patients underwent RP, respectively; $46.5 \%$ of patients from metropolitan and $34 \%$ of regional patients underwent RP. Overall, 2990 (21.3\%) cases of radiation treatment with curative intent were recorded; this includes external beam radiation therapy (EBRT) (15.7\%), brachytherapy (BT) (4.8\%) and combination 
EBRT and high dose BT (0.9\%). Further details of management are listed in Table 2.

Multivariable logistic regression analysis of factors associated with men not receiving active treatment within 12 months of diagnosis is shown in TableS1. Being over the age of 75 at diagnosis was associated with reduced likelihood of receiving active treatment and being diagnosed with higher risk disease was associated with increased likelihood of receiving active treatment.

\section{Mortality}

There was a total of 402 prostate cancer-related deaths in the period between diagnosis and follow-up in the study period of 2008-2015. Over half of the mortality notifications were from metropolitan institutions (247 [61.4\%]) and 223 (55.5\%) patients who died were diagnosed in a public hospital (TableS2). Stepwise multivariate Cox regression analysis of factors associated with mortality is shown in TableS3. Patients diagnosed with a Gleason score $>6$ were 2.1 times more likely to die (95\% CI: $1.78-2.41, \mathrm{p}<0.001)$ as compared to those with Gleason scores $\leq 6$, after accounting for other significant risk factors. Other factors significantly associated with increased risk of prostate cancer mortality are: diagnosis made in a regional hospital (HR 1.42; 95\% CI:1.09-1.84; $\mathrm{p}=0.010$ ), age $>55$ years at diagnosis (HR 1.49; 95\% CI:1.31-1.69; $\mathrm{p}<0.001$ ), PSA $>10 \mathrm{ng} / \mathrm{ml}$ 
at diagnosis (HR 1.52;95\% CI 1.27-1.81; p<0.001), Gleason score (HR 2.07;95\% CI 1.78-2.41; $<<0.001$ ), and NCCN risk category higher than low risk of disease progression (HR 2.22;95\% CI 1.92-2.56;p<0.001).

Comparison of patterns of care between 2008-2011 and 2011-2015

Comparisons of hospital characteristics and patient demographics data are shown in TableS4. There was an increase in the proportion of notifications received from private as well as regional hospitals, in the period from 20112015, reflecting the patterns of recruitment to the PCOR-Vic. The proportion of patients diagnosed with Gleason 9-10 disease increased, as has the proportion of patients diagnosed with metastatic disease in the same time period.

\section{Discussion}

By increasing coverage of the Victorian health network, PCOR-Vic provides potential for high quality data in a clinician-led governance framework to monitor care and outcomes. Here we documented an update to the previous patterns of care publication. It was noted that the majority of the prostate cancer notifications were from metropolitan hospitals and the private sector. The majority of patients were classified as having clinically localised disease, and 
intermediate risk of disease progression was the most commonly reported NCCN risk category. Regarding prostate cancer treatment, RP was the most common primary treatment with curative intent, and active surveillance has played a bigger part in the management of patients with low-risk of disease.

Localised prostate cancer makes up most of all diagnosed prostate cancers. Approximately $18 \%$ of localised prostate cancers are graded as low risk in the PCOR-Vic. From 1990 to 2010, more than 90\% of patients diagnosed with lowrisk prostate cancer received radical treatment ${ }^{21}$. Subsequent evidence regarding the indolent nature of low-grade disease (15-year mortality risk of 2$3 \%^{22}$ ) as well as the favourable outcome with conservative management resulted in the increased uptake in AS. AS has also become an important management option for prostate cancer patients in Victoria as we have identified that $55.89 \%$ of the low risk disease group received AS or watchful waiting.

Overall, surgical management remained the most common primary treatment with curative intent and the robotic RP has become the most common approach. This is likely partly because PCOR-Vic did not receive notifications from facilities performing robot-assisted RP (RARP) before December 2010 but also represents the growth of robotic surgery in Australia. The level of usage in Victoria, however, is still low compared to counterparts in USA, where in some regions $>75 \%$ of all RP's are performed using robotic approach ${ }^{23}$. It is clear from our 
data that RARP has superseded open surgery as the most common surgical option for prostate cancer in Victoria.

Since early 1990, PSA testing represents the mainstay of screening for prostate cancer. In October 2011, the U.S. Preventive Services Task Force (USPSTF) reviewed available evidence and concluded that PSA testing resulted in a negligible reduction in prostate cancer-related mortality ${ }^{24}$. In the final recommendation in May 2012, the USPSTF issued grade D recommendation against PSA screening ${ }^{8}$. In 2016, the new Australian guidelines were published ${ }^{25}$. Similarly, the guidelines do not recommend a population-based screening program for prostate cancer. The key recommendations are to offer evidencebased decisional support to men considering a PSA test accounting for benefits and harms. Most recently, the USPSTF has released a draft recommendation statement, issuing grade $\mathrm{C}$ recommendation for screening in men aged 55-699. This recommendation encourages individualized and informed decision-making about screening after discussion with a clinician 9.

In Australian, we have seen a clear decline of prostate cancer incidence over the last few years, which may be attributed to a decrease in PSA screening rates. Lo et $\mathrm{al}^{26}$ examined health service data from 2001 to 2014 to study prostate cancer screening rates in Australia. Findings suggest that PSA screening rates in Australia have been in decline since 2008, with highest rates of screening seen in 
patients aged 65-74 years (an annual average of 21,453 per 100,000 men)26. These findings were similar to the results from USA databases. Jemal et $\mathrm{al}^{27}$ analysed Surveillance, Epidemiology and End Results (SEER) data, and found an 18\% relative decrease in PSA testing, from 37.8\% in 2010 to $30.8 \%$ in 2013.

We have noted the proportion of patients diagnosed with Gleason 9-10 disease has increased, as has the proportion of patients diagnosed with metastatic disease in the period of 2011-2015 compared to 2008-2011. This corresponds to some of the current available evidence. A number of studies utilised the National Cancer Database (NCDB) and reported increased diagnoses of clinical stage T3a or higher, including metastatic disease ${ }^{28,29}$. Other studies of the NCDB data also showed a decrease in low-risk cases, from $31.9 \%$ in 2011 to $25.9 \%$ in 2013 , and a corresponding increase in intermediate- risk (43.5\% to $45.1 \%)$ and high-risk (24.5\% to $29 \%$ ) cases $^{28}$. We suspect this finding could be due to the fact that the screening rates in younger men, who are more likely to harbour lower grade and stage of disease, have decreased more than the screening rates of elderly men. This could have caused a shift to higher proportion of high risk and metastatic disease. This is supported Lo et $\mathrm{al}^{26}$, whose results demonstrated significant downward trend of PSA screening rates since 2008 for all age groups except for men aged over 85 years.

This article is protected by copyright. All rights reserved. 
We assessed whether patient demographics were associated with different outcomes. The majority of notifications received by PCOR-Vic came from metropolitan institutions and the private sector. These patterns were similar compared to the previous period of analysis. We also noted that a higher percentage of prostate cancer specific mortality occurred in the public sector compared to private. Our findings were similar to a Western Australian population-based study examining the effects of demographic, geographical and socio-economic factors, and the influence of private health insurance, on prostate cancer care and 3-year survival ${ }^{30}$. Results demonstrated poorer 3-year survival in men from socioeconomically and geographically disadvantaged backgrounds, particularly those admitted to regional or public hospitals ${ }^{30}$. Interestingly, our data did not demonstrate regional hospitals having higher rates or significant association with mortality. This could be partly explained by the significantly higher notification rate from the metropolitan hospitals.

The limitations of our study need to be acknowledged. The PCOR-Vic does not have $100 \%$ population coverage (current population coverage is $75 \%$ ); therefore, it is not possible to extract accurate incidence data. There are a proportion of patients with incomplete data and this contributes to the inaccuracies of interpretations. In our dataset, a proportion of clinical T-stage data was missing. This is because it is not routinely recorded in some practices or hospitals. Regarding analysis of predictor of survival, year of diagnosis was 
explored to be a predictor, however due to its collinearity with the multivariate cox regression model, this was unable to be assessed fully. As the PCOR-Vic records treatment information in 12-monthly intervals, patients initially on AS progressing to active treatment within 12 months may not be recorded as initially being on AS. This could lead to underestimation of the number of patients on AS. Lastly, the registry does not collect information regarding medical co-morbidities or frailty indices.

\section{Conclusion}

With the PCOR-Vic, we were able to identify that increasing number of patients were diagnosed with high-risk and metastatic disease. There has been an overall decrease in radical treatment rates, especially in patients with low risk prostate cancer, likely due to active surveillance playing a significant role. This update of patterns of care for Victorian prostate cancer patients is important for monitoring trends over time to ensure quality of care, especially in the rapidly changing landscape of prostate cancer management.

\section{References}

This article is protected by copyright. All rights reserved. 
1. Siegel RL, Miller KD, Jemal A. Cancer Statistics, 2017. CA Cancer J Clin 2017;67:7-30.

2. Welfare AIoHa. Australian Cancer Incidence and Mortality (ACIM) books: Prostate cancer. Canberra:AIHW 2017.

3. Frydenberg M, Giles GG, Mameghan H, et al. Prostate cancer in Victoria in 1993: patterns of reported management. Med J Aust 2000;172:270-4.

4. Evans SM, Millar JL, Davis ID, et al. Patterns of care for men diagnosed with prostate cancer in Victoria from 2008 to 2011. Med J Aust 2013;198:540-5. 5. Weerakoon M, Papa N, Lawrentschuk N, et al. The current use of active surveillance in an Australian cohort of men: a pattern of care analysis from the Victorian Prostate Cancer Registry. BJU Int 2015;115 Suppl 5:50-6.

6. Evans SM, Millar JL, Frydenberg M, et al. Positive surgical margins: rate, contributing factors and impact on further treatment: findings from the Prostate Cancer Registry. BJU Int 2014;114:680-90.

7. Sampurno F, Earnest A, Kumari PB, et al. Quality of care achievements of the Prostate Cancer Outcomes Registry-Victoria. Med J Aust 2016;204:319.

8. Moyer VA, Force USPST. Screening for prostate cancer: U.S. Preventive Services Task Force recommendation statement. Ann Intern Med 2012;157:12034.

9. USPSTF. Prostate Cancer Screening Draft Recommendations. 2017. 10. Bill-Axelson A, Holmberg L, Garmo H, et al. Radical prostatectomy or watchful waiting in early prostate cancer. N Engl J Med 2014;370:932-42. 
11. Wilt TJ, Brawer MK, Jones KM, et al. Radical prostatectomy versus observation for localized prostate cancer. N Engl J Med 2012;367:203-13. 12. Wilt TJ, Jones KM, Barry MJ, et al. Follow-up of Prostatectomy versus Observation for Early Prostate Cancer. N Engl J Med 2017;377:132-42.

13. Hamdy FC, Donovan JL, Lane JA, et al. 10-Year Outcomes after Monitoring, Surgery, or Radiotherapy for Localized Prostate Cancer. N Engl J Med 2016;375:1415-24.

14. Tosoian JJ, Carter HB, Lepor A, Loeb S. Active surveillance for prostate cancer: current evidence and contemporary state of practice. Nat Rev Urol 2016;13:205-15.

15. Murphy DG, Loeb S. Prostate cancer: Growth of AS in the USA signals reduction in overtreatment. Nat Rev Urol 2015;12.

16. Murphy DG, Ahlering T, Catalona WJ, et al. The Melbourne Consensus Statement on the Early Detection of Prostate Cancer. BJU Int 2014;113:2.

17. Barocas DA, Mallin K, Graves AJ, et al. The effect of the United States Preventive Services Task Force grade D recommendation against screening for prostate cancer on incident prostate cancer diagnoses in the US. J Urol 2015;194. 18. Bhindi B, Mamdani M, Kulkarni GS, et al. Impact of the U.S. Preventive Services Task Force Recommendations against Prostate Specific Antigen Screening on Prostate Biopsy and Cancer Detection Rates. J Urol 2015;193:151924. 
19. Zargar H, van den Bergh R, Moon D, Lawrentschuk N, Costello A, Murphy

D. The impact of the United States Preventive Services Task Force (USPTSTF) recommendations against prostate-specific antigen (PSA) testing on PSA testing in Australia. BJU Int 2017;119:110-5.

20. Evans SM, Millar JL, Wood JM, et al. The Prostate Cancer Registry:

monitoring patterns and quality of care for men diagnosed with prostate cancer. BJU Int 2013;111:E158-66.

21. Cooperberg MR, Broering JM, Carroll PR. Time trends and local variation in primary treatment of localized prostate cancer. J Clin Oncol 2010;28:1117-23. 22. Klotz L. Active surveillance for low-risk prostate cancer. Curr Opin Urol 2017;27:225-30.

23. Novara G, Ficarra V, Rosen RC, et al. Systematic review and meta-analysis of perioperative outcomes and complications after robot-assisted radical prostatectomy. Eur Urol 2012;62:431-52.

24. Chou R, Croswell JM, Dana T, et al. Screening for prostate cancer: a review of the evidence for the U.S. Preventive Services Task Force. Ann Intern Med 2011;155:762-71.

25. Lawrentschuk N. PSA testing and early management of test-detected prostate cancer--consensus at last. BJU Int 2016;117 Suppl 4:5-6.

26. Lo J, Papa N, Bolton DM, Murphy D, Lawrentschuk N. Australian patterns of prostate cancer care: Are they evolving? Prostate Int 2016;4:20-4.

This article is protected by copyright. All rights reserved. 
27. Jemal A, Fedewa SA, Ma J, et al. Prostate Cancer Incidence and PSA Testing Patterns in Relation to USPSTF Screening Recommendations. JAMA 2015;314:2054-61.

28. Fleshner K, Carlsson SV, Roobol MJ. The effect of the USPSTF PSA screening recommendation on prostate cancer incidence patterns in the USA. Nat Rev Urol 2017;14:26-37.

29. Weiner AB, Matulewicz RS, Eggener SE, Schaeffer EM. Increasing incidence of metastatic prostate cancer in the United States (2004-2013). Prostate Cancer Prostatic Dis 2016;19:395-7.

30. Hall SE, Holman CD, Wisniewski ZS, Semmens J. Prostate cancer: socioeconomic, geographical and private-health insurance effects on care and survival. BJU Int 2005;95:51-8. 
Supporting information:

This article is protected by copyright. All rights reserved. 
$\underline{\text { TableS1 }}$

Multivariable logistic regression analysis of factors associated with men not receiving active treatment within 12 months of diagnosis (2008-2015)

TableS2

Comparison of proportions of prostate cancer specific mortality by hospital and risk of disease progression between Aug 2008-Feb 2011 and Mar 2011-Dec 2015.

$\underline{\text { TableS3 }}$

Stepwise multivariate cox regression analysis of factors associated with mortality.

$\underline{\text { TableS4 }}$

Comparisons of hospital characteristics and patient demographics between Aug 2008-Feb 2011 and Mar 2011-Dec 2015.

FigureS1

Patient recruitment for the PCOR. 


\section{Tables:}

Table 1: Hospital and patient characteristics

\begin{tabular}{|l|l|}
\hline Hospital Characteristics & Number (\%) of patients \\
\hline Type of Hospital & \\
\hline Public & $4,350(31 \%)$ \\
\hline Private & $8,923(63.6 \%)$ \\
\hline Interstate/Overseas & $189(1.4 \%)$ \\
\hline Unknown & $563(4 \%)$ \\
\hline Location of Hospital & $9,847(70.2 \%)$ \\
\hline Metro & $3,318(23.7 \%)$ \\
\hline Regional & $189(1.4 \%)$ \\
\hline Interstate/Overseas & $671(4.8 \%)$ \\
\hline Unknown & $5,231(37.3 \%)$ \\
\hline Patient Characteristics-Age & $1,689(12 \%)$ \\
\hline$<55$ years & $5,083(36.2 \%)$ \\
\hline $55-64$ years & \\
\hline $65-74$ years & \\
\hline
\end{tabular}

This article is protected by copyright. All rights reserved. 


\begin{tabular}{|c|c|}
\hline $75-84$ years & $1,722(12.3 \%)$ \\
\hline$>=85$ years & $300(2.1 \%)$ \\
\hline \multicolumn{2}{|l|}{ Gleason Score } \\
\hline 6 or less & $4,472(31.9 \%)$ \\
\hline 7 & $6,171(44 \%)$ \\
\hline 8 & $1,367(9.8 \%)$ \\
\hline 9 & $1,407(10 \%)$ \\
\hline 10 & $121(0.9 \%)$ \\
\hline Unknown & $487(3.5 \%)$ \\
\hline \multicolumn{2}{|l|}{ Prostate-specific antigen (PSA) level } \\
\hline$<=10 \mathrm{ng} / \mathrm{mL}$ & $9,693(69.1 \%)$ \\
\hline $10.01-20 \mathrm{ng} / \mathrm{mL}$ & $2,226(15.9 \%)$ \\
\hline$>20 \mathrm{ng} / \mathrm{mL}$ & $1,614(11.5 \%)$ \\
\hline Unknown & $492(3.5 \%)$ \\
\hline \multicolumn{2}{|l|}{ Risk of disease progression } \\
\hline Low risk (clinically localised) & $3,466(24.7 \%)$ \\
\hline Intermediate risk (clinically localised) & $6,070(43.3 \%)$ \\
\hline High risk (clinically localised) & $3,024(21.6 \%)$ \\
\hline Very high risk (locally advanced) & $149(1 \%)$ \\
\hline Metastatic disease & $875(6.2 \%)$ \\
\hline Unknown & $441(3.1 \%)$ \\
\hline \multicolumn{2}{|l|}{ cT Stage } \\
\hline $\mathrm{T} 1$ & $5,772(41.2 \%)$ \\
\hline
\end{tabular}

This article is protected by copyright. All rights reserved. 


\begin{tabular}{|l|l|}
\hline T2 & $3,702(26.4 \%)$ \\
\hline T3 & $1,053(7.5 \%)$ \\
\hline Unknown & $147(1.1 \%)$ \\
\hline cN Stage & $3,351(23.9 \%)$ \\
\hline 1- NX & $95(0.7 \%)$ \\
\hline 2- N0 & $13,271(94.6 \%)$ \\
\hline 3 - N1 & $437(3.1 \%)$ \\
\hline 4- Unknown & $222(1.6 \%)$ \\
\hline cM Stage & $68(0.5 \%)$ \\
\hline MX & $12,995(92.7 \%)$ \\
\hline M0 & $202(1.4 \%)$ \\
\hline M1 & $23(0.2 \%)$ \\
\hline M1a & $481(3.4 \%)$ \\
\hline M1b & $208(1.5 \%)$ \\
\hline M1c & \\
\hline Unknown & \\
\hline
\end{tabular}

This article is protected by copyright. All rights reserved. 
Table 2: Overall treatment in the initial 12-month period following diagnosis according to NCCN risk category (2008-2015).

This article is protected by copyright. All rights reserved. 


\begin{tabular}{|c|c|c|c|c|c|c|c|c|}
\hline & Low Risk & $\begin{array}{l}\text { Intermediate } \\
\text { Risk }\end{array}$ & $\begin{array}{l}\text { High } \\
\text { Risk }\end{array}$ & $\begin{array}{l}\text { Total (clinically } \\
\text { localised } \\
\text { categories) }\end{array}$ & $\begin{array}{l}\text { Very } \\
\text { High } \\
\text { Risk }\end{array}$ & $\begin{array}{l}\text { Metastatic } \\
\text { Disease }\end{array}$ & $\begin{array}{l}\text { Unable to } \\
\text { Classify } \\
\text { (likely low } \\
\text { risk) }\end{array}$ & $\begin{array}{l}\text { Total (all risk } \\
\text { categories) }\end{array}$ \\
\hline No Active Treatment & $\begin{array}{l}1937 \\
(55.89 \%)\end{array}$ & $932(15.35 \%)$ & $\begin{array}{l}260 \\
(8.60 \%)\end{array}$ & $3129(24.91 \%)$ & $\begin{array}{l}4 \\
(2.68 \%)\end{array}$ & $21(2.40 \%)$ & $195(44.22 \%)$ & $\begin{array}{l}3,349 \\
(23.88 \%)\end{array}$ \\
\hline Radical Prostatectomy & $\begin{array}{l}1136 \\
(32.78 \%)\end{array}$ & $\begin{array}{l}3551 \\
(58.50 \%)\end{array}$ & $\begin{array}{l}1144 \\
(37.83 \%)\end{array}$ & $5831(46.43 \%)$ & $\begin{array}{l}24 \\
(16.11 \%)\end{array}$ & $82(9.37 \%)$ & $129(29.25 \%)$ & $\begin{array}{l}6066 \\
(43.25 \%)\end{array}$ \\
\hline $\begin{array}{l}\text { Radical Prostatectomy and } \\
\text { External Beam Radiation } \\
\text { Therapy }\end{array}$ & $\begin{array}{l}30 \\
(0.87 \%)\end{array}$ & $210(3.46 \%)$ & $\begin{array}{l}235 \\
(7.77 \%)\end{array}$ & $475(3.78 \%)$ & $\begin{array}{l}11 \\
(7.38 \%)\end{array}$ & $22(2.51 \%)$ & $11(2.49 \%)$ & $519(3.70 \%)$ \\
\hline $\begin{array}{l}\text { External Beam Radiation } \\
\text { Therapy }\end{array}$ & $\begin{array}{l}105 \\
(3.03 \%)\end{array}$ & $835(13.76 \%)$ & $\begin{array}{l}890 \\
(29.43 \%)\end{array}$ & $1830(14.57 \%)$ & $\begin{array}{l}69 \\
(46.31 \%)\end{array}$ & $\begin{array}{l}258 \\
(29.49 \%)\end{array}$ & $40(9.07 \%)$ & $\begin{array}{l}2197 \\
(15.66 \%)\end{array}$ \\
\hline Brachytherapy-Unknown & $\begin{array}{l}16 \\
(0.46 \%)\end{array}$ & $35(0.58 \%)$ & $7(0.23 \%)$ & $58(0.46 \%)$ & 0 & $1(0.11 \%)$ & $12(2.72 \%)$ & $71(0.51 \%)$ \\
\hline $\begin{array}{l}\text { Low Dose Rate } \\
\text { Brachytherapy }\end{array}$ & $\begin{array}{l}212 \\
(6.12 \%)\end{array}$ & $334(5.50 \%)$ & $7(0.23 \%)$ & $553(4.40 \%)$ & 0 & $1(0.11 \%)$ & $7(1.59 \%)$ & $561(4.00 \%)$ \\
\hline $\begin{array}{l}\text { High Dose Rate } \\
\text { Brachytherapy }\end{array}$ & $2(0.06 \%)$ & $24(0.40 \%)$ & $8(0.26 \%)$ & $34(0.27 \%)$ & 2 & $0(0.00 \%)$ & $0(0.00 \%)$ & $36(0.26 \%)$ \\
\hline $\begin{array}{l}\text { External Beam Radiation } \\
\text { Therapy and High Dose Rate } \\
\text { Brachytherapy }\end{array}$ & $0(0.00 \%)$ & $38(0.63 \%)$ & $\begin{array}{l}81 \\
(2.68 \%)\end{array}$ & $119(0.95 \% 0$ & $\begin{array}{l}3 \\
(2.01 \%)\end{array}$ & $1(0.11 \%)$ & $2(0.45 \%)$ & $125(0.89 \%)$ \\
\hline $\begin{array}{l}\text { Androgen Deprivation } \\
\text { Therapy }\end{array}$ & $\begin{array}{l}14 \\
(0.40 \%)\end{array}$ & $96(1.58 \%)$ & $\begin{array}{l}384 \\
(12.70 \%)\end{array}$ & $494(3.93 \%)$ & $\begin{array}{l}35 \\
(23.49 \%)\end{array}$ & $\begin{array}{l}421 \\
(48.11 \%)\end{array}$ & $38(8.62 \%)$ & $988(7.04 \%)$ \\
\hline
\end{tabular}

This article is protected by copyright. All rights reserved. 


\begin{tabular}{|c|c|c|c|c|c|c|c|c|}
\hline HIFU & $\begin{array}{l}12 \\
(0.35 \%)\end{array}$ & $12(0.20 \%)$ & $1(0.03 \%)$ & $25(0.20 \%)$ & $\begin{array}{l}0 \\
(0.00 \%)\end{array}$ & $1(0.11 \%)$ & $0(0.00 \%)$ & $26(0.19 \%)$ \\
\hline Chemotherapy & $1(0.03 \%)$ & $2(0.03 \%)$ & $4(0.13 \%)$ & $7(0.06 \%)$ & $\begin{array}{l}1 \\
(0.67 \%)\end{array}$ & $66(7.54 \%)$ & $6(1.36 \%)$ & $80(0.57 \%)$ \\
\hline Other & $1(0.03 \%)$ & $1(0.02 \%)$ & $3(0.10 \%)$ & $5(0.04 \%)$ & $\begin{array}{l}0 \\
(0.00 \%)\end{array}$ & $1(0.11 \%)$ & $1(0.23 \%)$ & $7(0.05 \%)$ \\
\hline $\begin{array}{l}\text { Total (all treatment } \\
\text { categories) }\end{array}$ & $\begin{array}{l}3466 \\
(24.71 \%)\end{array}$ & $\begin{array}{l}6070 \\
(43.28 \%)\end{array}$ & $\begin{array}{l}3024 \\
(21.56 \%)\end{array}$ & $12560(89.55 \%)$ & $\begin{array}{l}149 \\
(1.06 \%)\end{array}$ & $\begin{array}{l}875 \\
(6.24 \%)\end{array}$ & $441(3.14 \%)$ & $14,025(100 \%)$ \\
\hline
\end{tabular}


This article is protected by copyright. All rights reserved. 


\section{University Library}

\section{- M M N E R VA A gateway to Melbourne's research publications}

Minerva Access is the Institutional Repository of The University of Melbourne

Author/s:

Wang, LL;Begashaw, K;Evans, M;Earnest, A;Evans, SM;Millar, JL;Murphy, DG;Moon, D

Title:

Patterns of care and outcomes for men diagnosed with prostate cancer in Victoria: an update

Date:

2018-10-01

Citation:

Wang, L. L., Begashaw, K., Evans, M., Earnest, A., Evans, S. M., Millar, J. L., Murphy, D. G. \& Moon, D. (2018). Patterns of care and outcomes for men diagnosed with prostate cancer in Victoria: an update. [Abstract]. ANZ JOURNAL OF SURGERY, 88 (10), pp.1037-1042. https://doi.org/10.1111/ans. 14722.

Persistent Link:

http://hdl.handle.net/11343/283425 